http://www.jfas.info

\title{
CONCEPTUAL DESIGN OF HYDRAULIC HYBRID TEST RIG FOR ENGINE PERFORMANCE ENHANCEMENT
}

\author{
S. Y. Asrul ${ }^{1,2, *}$, M. S. Risby ${ }^{1}$, A. R. Sarip ${ }^{1}$, M. I. Saiddi ${ }^{1}$ and W. A. W. Mat ${ }^{1}$ \\ ${ }^{1}$ Faculty of Engineering, Universiti Pertahanan Nasional Malaysia, Sungai Besi Camp, 57000 \\ Kuala Lumpur, Malaysia \\ ${ }^{2}$ Universiti Kuala Lumpur Malaysia France Institute, 43650 Bandar Baru Bangi, Selangor, \\ Malaysia
}

Published online: 10 September 2017

\begin{abstract}
A large amount of torque is needed in moving heavy duty vehicle and machinery to achieve high acceleration speed or to perform activities at any off-road condition or rough terrain in a short time. This additional torque can be harness from hydraulic hybrid system. Hydraulic hybrid has been considered as an alternative to fulfil the increased demands on higher efficiency and better systems, components and functionality of a vehicle. In this paper, a conceptual design of hydraulic hybrid test rig for engine performance enhancement was proposed using a dynamometer test setup. A differential gear mechanism was identified as the vital component of the transmission system to couple both power generated from engine and hydraulic hybrid system.
\end{abstract}

Keywords: machine; power coupler; diesel engine; accumulator; hydraulic motor.

Author Correspondence, e-mail: asrulsyaharani@unikl.edu.my

doi: http://dx.doi.org/10.4314/jfas.v9i3s.6 


\section{INTRODUCTION}

Most of the research study related to hydraulic hybrid system was made to improve fuel consumption and increase the efficiency of the energy usage. However, there is a lack in study, which focus on the increase of the vehicle rapid acceleration. The common hybrid hydraulic strategy is to initiate the vehicle acceleration from fully stop condition by using only hydraulic power and when the pressure in high-pressure accumulator almost depleted, the internal combustion engine will take over to propel the vehicle [1]. To increase the vehicle rapid acceleration, the hydraulic hybrid system use the hydraulic energy stored in the accumulator and coupling simultaneously with the engine power for the acceleration boost to improve the vehicle acceleration. In this case, a power-split transmission is preferable because it can combine two different input powers (engine power and hydraulic power) and deliver it through one output (drive axle) [2-3] as shown in Fig. 1. However, this type of transmission is too costly to be adopted because of its complexity of the control system and gearing ratio of the planetary gear.

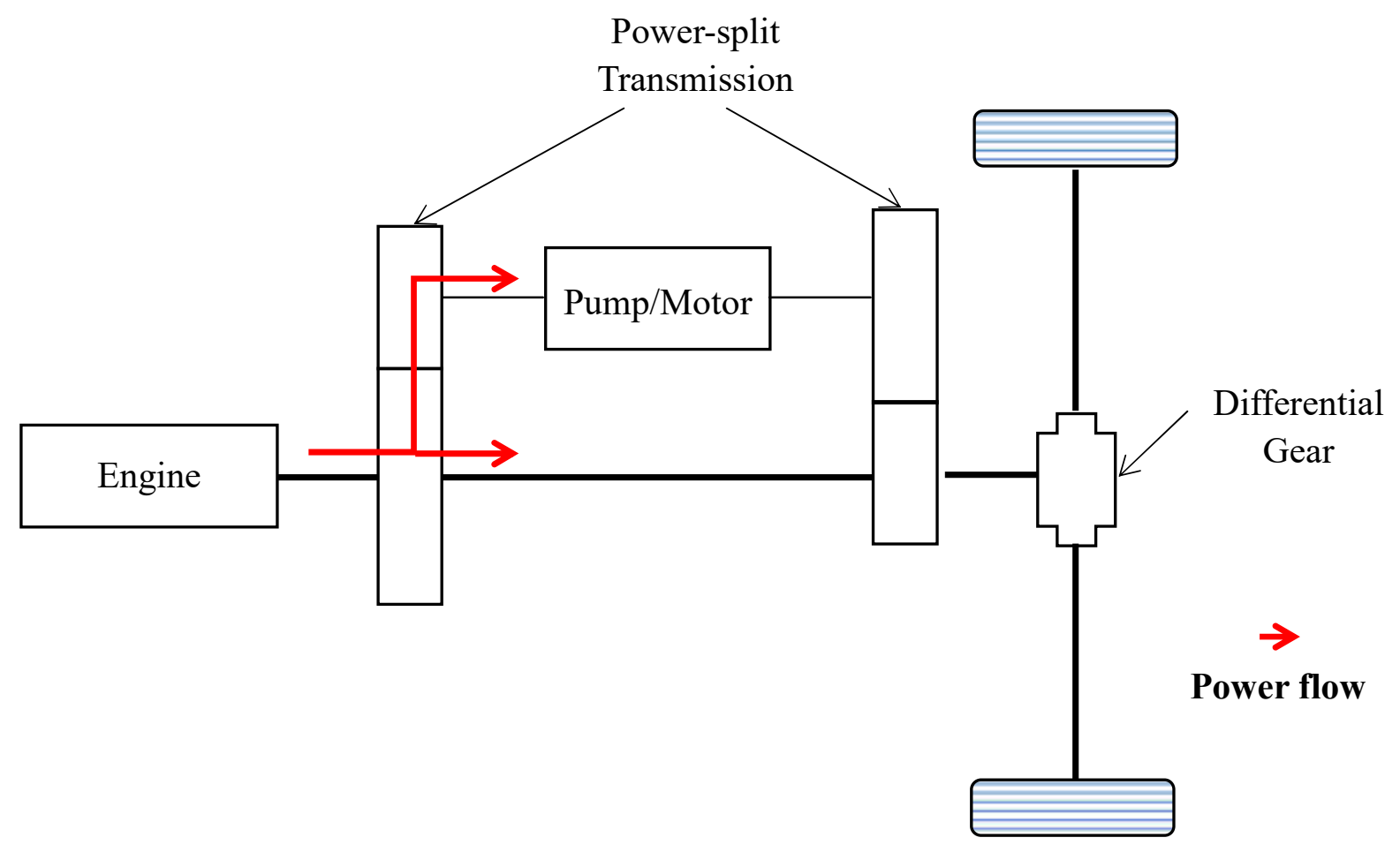

Fig.1. Power flow path for power-split transmission 


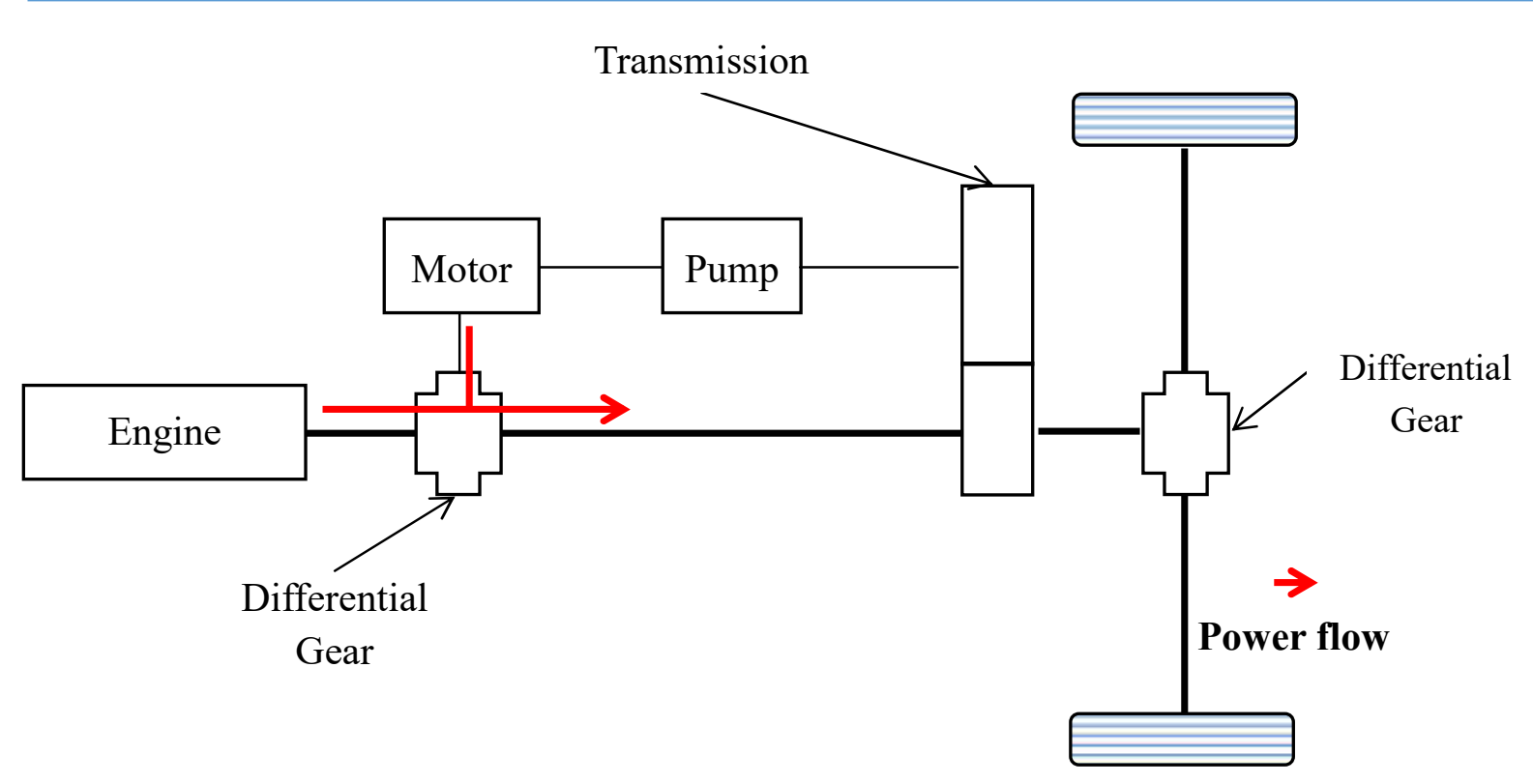

Fig.2. Power flow path for power-coupler transmission

Another approach in combining the two input powers (engine power and hydraulic power) is by introducing a power-coupler into the vehicle driveline [4] as shown in Fig. 2. This power-coupler can be position between engine and transmission or transmission and drive axle. The power-coupler system can be based on planetary gear or differential gear.

In [1] have introduce a common pressure rail (CPR) and hydraulic transformer (HT) in order to achieved a better vehicle performance and fuel economy by optimizing an accumulator size. Meanwhile, in [5-6] have studied about optimal design of input coupled power-splits using a planetary gear where the planetary gear acting as a power coupling devices. Power management and component sizing such as hydraulic motor/pump need to be optimized and match with the vehicle characteristic, so that it can achieve optimal fuel consumption [2-4] has adopted planetary gear transmission principle as a power combining devices. Based on simulation results through MATLAB/Simulink, in [4] found that by combining the torque from engine and hydraulic motor, the coupled torque can increase the total torque and provided the vehicle a short burst of power for a limited time as shown in Fig. 3. 


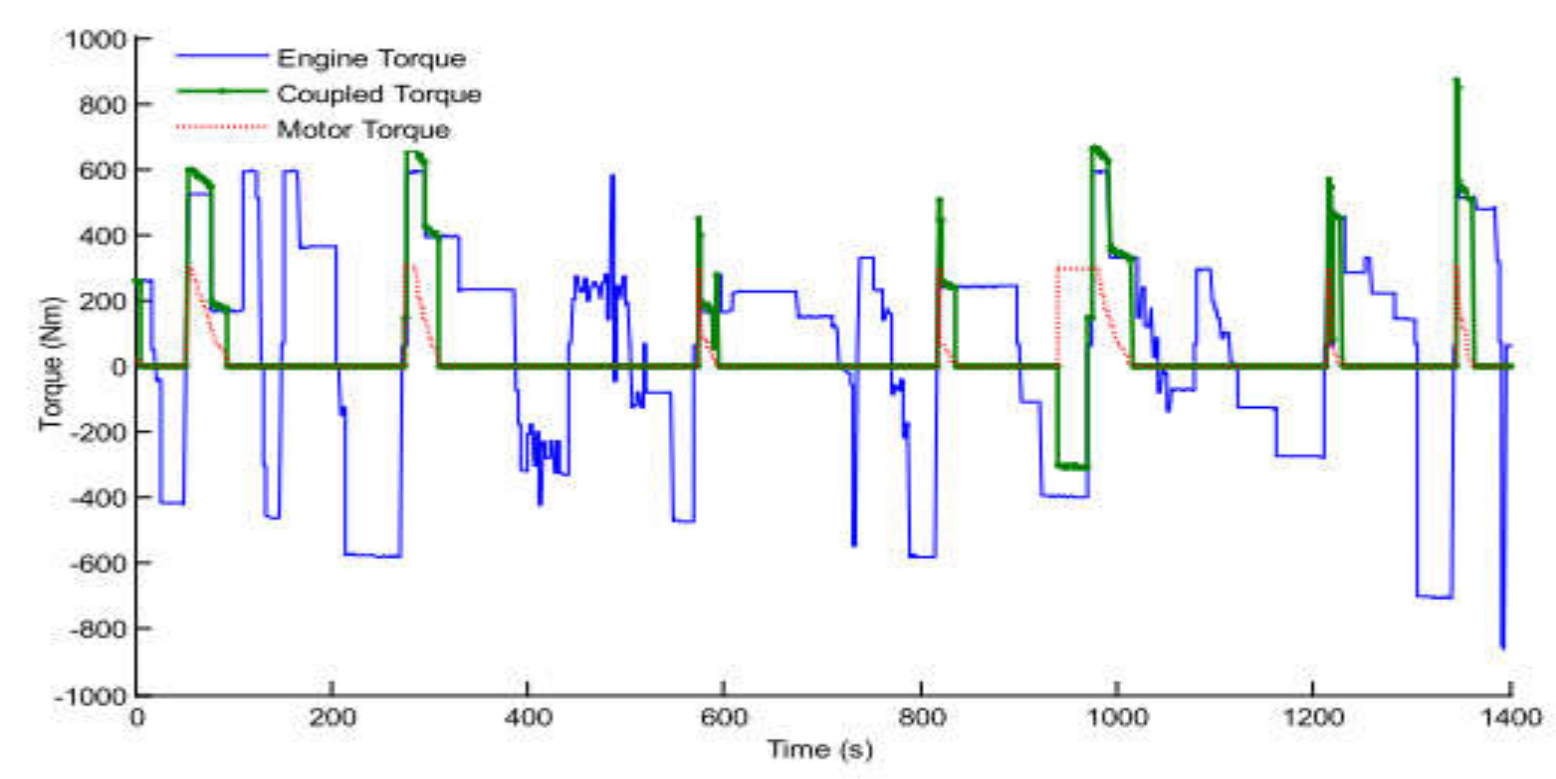

Fig.3. Coupling torque characteristic curve [4]

In Malaysia, just a few studies have been made regarding hydraulic hybrid system. It is found that most of the studies are simulation based work. In [7] has simulated using EPA Advance Vehicle Simulator (ADVISOR) 2002 software about emission performance of parallel hydraulic hybrid on Proton 1.5L engine and it shows a significant reduction of exhaust gas emission on US06 drive cycle. Meanwhile, in [8] have designed and modeled a control strategy through MATLAB/Simulink for a parallel hydraulic hybrid bus and found out that at least $26 \%$ reduction of fuel consumption when simulated on Tehran and the Nuremburg drive cycles. None of researchers have studied or mention about power coupling system.

From the author's knowledge, there is no comprehensive study is being carried out to investigate using experimental approach on the energy required by the hydraulic system to increase the engine torque during acceleration while the power from the engine added at the same time. This paper proposes the design concept of a hybrid hydraulic testing rig where the power output from both generated device and the effectiveness of the hydraulic system will be tested and verified once the system have been fabricated.

\section{METHODOLOGY}

The hypothesis of this study is that the engine torque which, represents vehicle acceleration can be increase significantly by optimizing the hydraulic fluid flowrate and accumulator 
pre-charge pressure so that it can achieve a better acceleration. By referring to Fig. 4, the hydraulic pump/motor power is defined by Equation (1) [9]:

$\omega_{p / m}=T_{p / m} * \omega_{p / m}$

where $T_{p / m}$ is the pump/motor torque. $\omega_{p / m}$ is the pump/motor angular speed. The torque is $T_{p / m}=\Delta p D$, where $\Delta p$ is the pressure difference across the pump/motor $\left(p_{h p}-p_{l p}\right)$ and $D$ is the pump/motor displacement per radian. $p_{h p}$ is the pressure in high pressure accumulator and $p_{l p}$ is the pressure in low pressure accumulator.

(Assumed that pressure in the low-pressure accumulator is significantly less than that in the high-pressure accumulator, so we set $\Delta p=p_{h p}=p$ ). The volumetric flowrate through the pump/motor is $Q=\omega D$. Since the angular speed of the shaft is proportional to vehicle speed, speed of this pump/motor can be controlled by either controlling inlet pressure ( $\Delta p$ across the motor) or the flow rate [9].

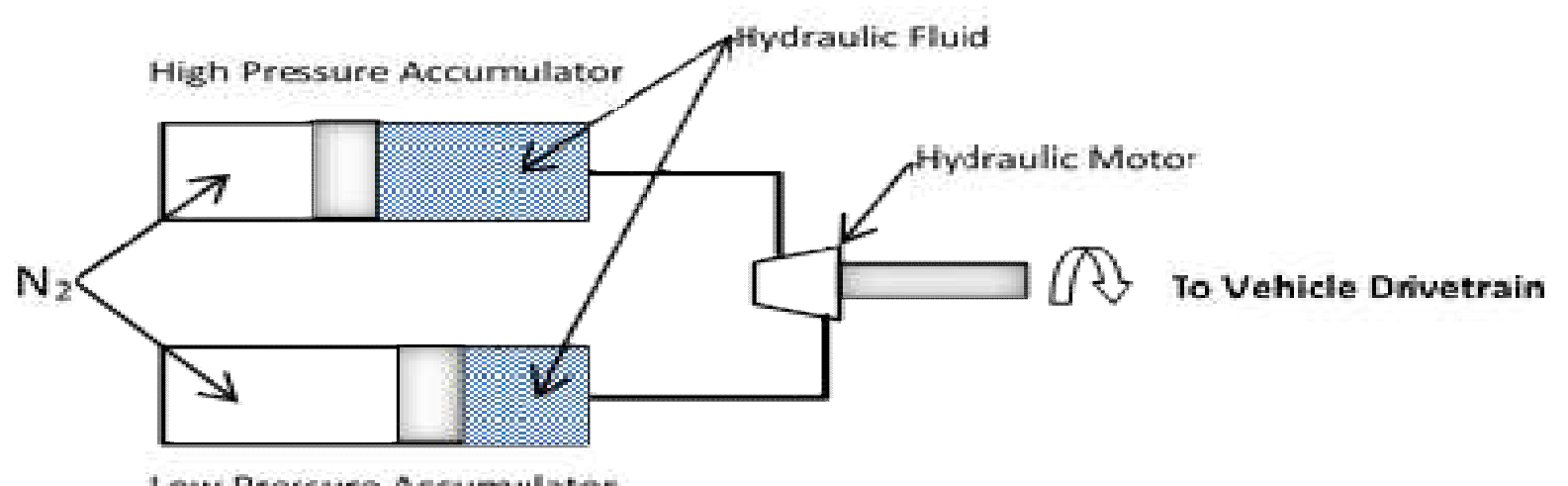

Fig.4. Hydraulic pump/motor unit with high and low pressure accumulator

To represent the relation between the output torque of the power coupler, hydraulic motor torque and the engine torque, the equation is defined by [4] as:

$P_{o}=T_{E} * \omega_{E}+T_{T} * \omega_{T}+T_{p / m} * \omega_{p / m}$

where $P_{o}$ is the power output, $T_{E}$ is the engine torque, $\omega_{E}$ is the angular speed of engine, $T_{T}$ is the output torque of power-coupler, $\omega_{T}$ is the angular speed of power coupler, $T_{p / m}$ is output torque of the hydraulic motor and $\omega_{p / m}$ is the angular speed of the hydraulic motor. Numerous research on the hydraulic hybrid technology have focused on heavy-duty vehicles such as buses and trucks, as the heavy mass of these vehicles produces a generous amount of energy which can potentially be reused [2-4].

There are 3 main types of hydraulic hybrid system configuration namely [10] a hydraulic 
pump/motor has a direct connection between the engine and drive axle which can recover kinetic energy during deceleration (as indicated in the line arrow in Fig. 5). Accumulator is charge directly through the pump/motor. The recovered energy in the accumulator is passed through the pump/motor when accelerating from a stop. This type of hybrid allows the vehicle to be driven by the engine or pump/motor individually or by a combination of the two.

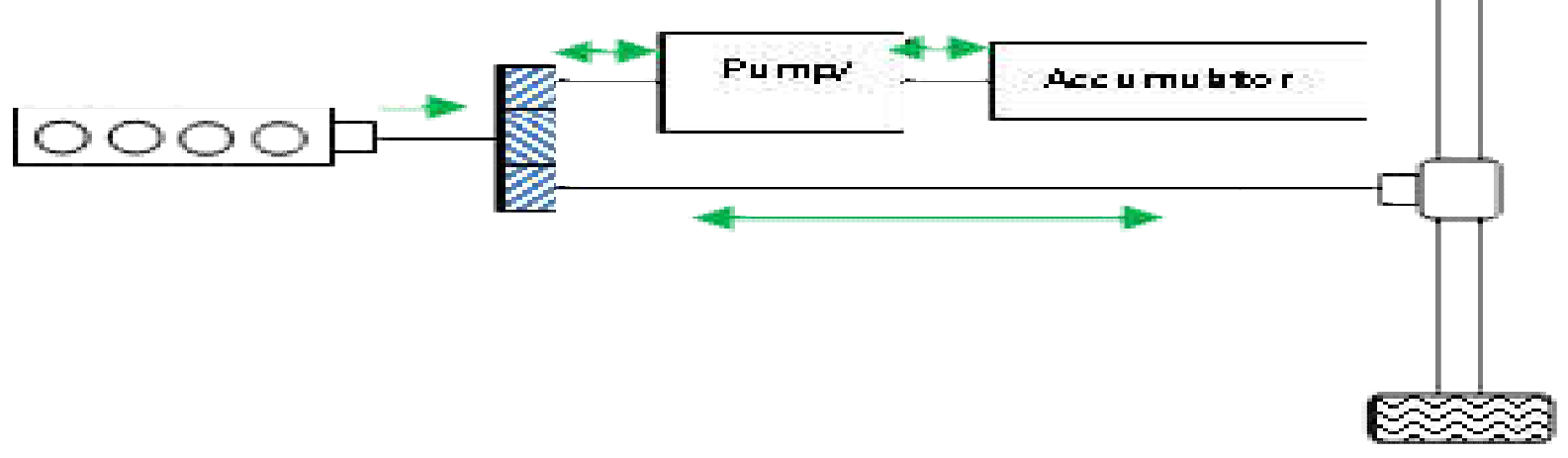

Fig.5. Parallel hydraulic hybrid

A series hybrid does not have a direct connection between the engine and drive axle. Instead, energy from the engine must pass through a pair of pump/motor before reaching the drive axle (as indicated in the line arrow in Fig. 6). Energy passed through the first pump/motor can be stored in the accumulator, passed through the second accumulator or split between the accumulator and second pump/motor. This configuration recovers kinetic energy through the second pump/motor.

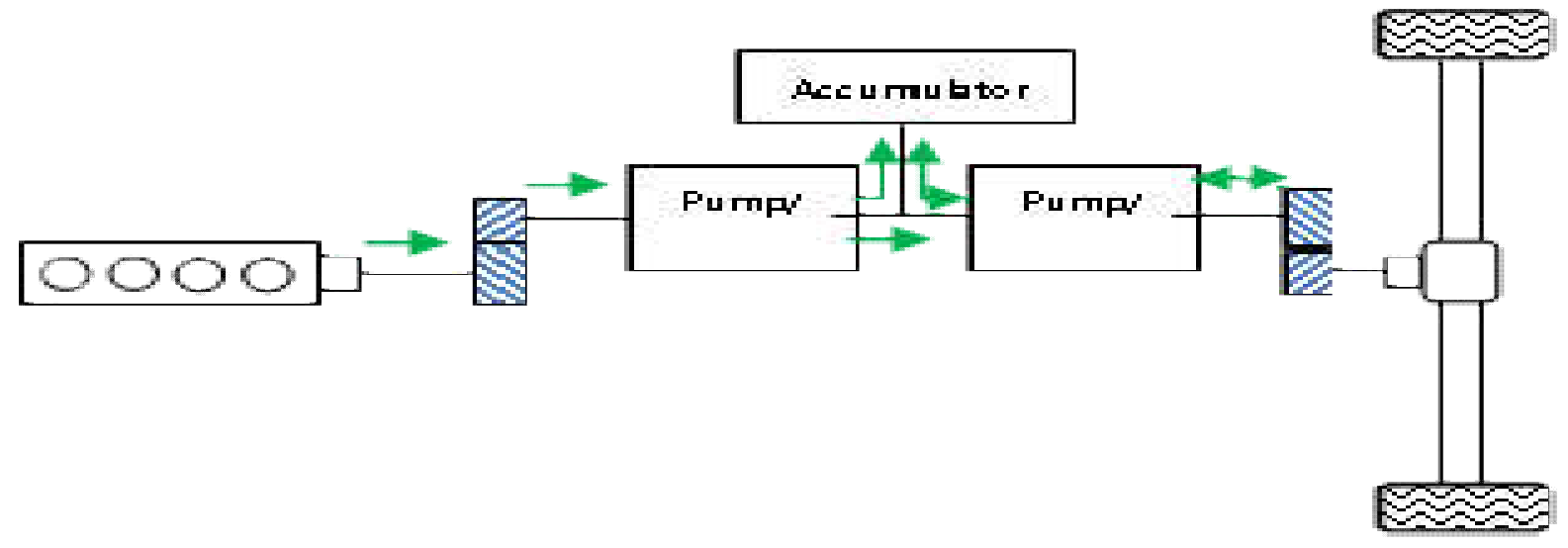

Fig.6. Series hydraulic hybrid

Parallel-series hybrids are a combination of the parallel and series configurations. The engine in this configuration is connected to the first pump/motor and the drive axle (as indicated in the line arrow in Fig. 7). The second pump/motor is connected to the drive axle and shares an 
accumulator with the first pump/motor. A parallel-series hybrid allows the vehicle to be driven directly by the engine or by the engine and second pump/motor. Energy from the engine can also be split between the drive axle and the first pump/motor. Kinetic energy recovery is performed through the second pump/motor.

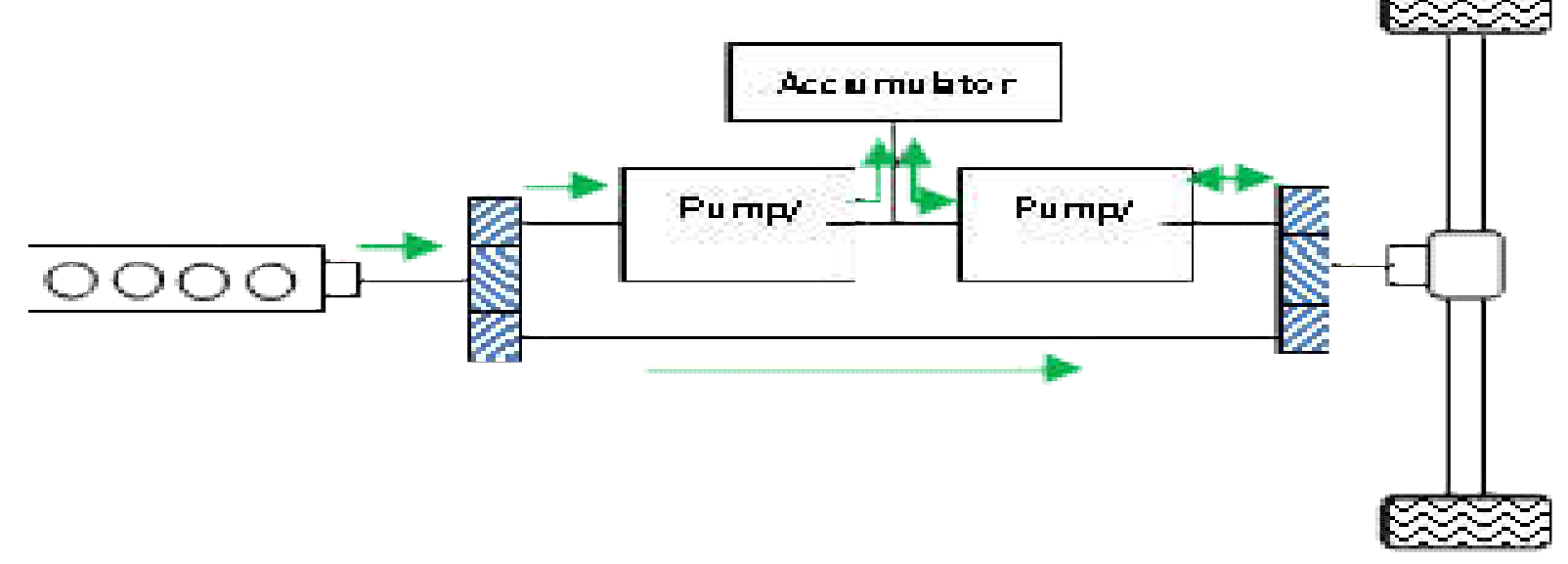

Fig.7. Parallel-series hydraulic hybrid

\section{RESULTS AND DISCUSSION}

The main challenge in designing a hybrid hydraulic system is to identify the suitable coupling mechanism, which can combine both power and torque input from the engine and the hydraulic system. Most hybrid hydraulic studies especially related to electrical motor utilized planetary gear system as the suitable coupling mechanism. However, since this study objective is focused on heavy duty vehicles that commonly used diesel engine, it is proposed that the test rig to use similar engine type but at a scaled down range engine capacity of $3200 \mathrm{cc}$. A gearing system must be utilized to couple the power generated from the engine and the hydraulic motor. Planetary gearing system is not suitable for this purpose due to its complexity on the installation and fitting to the proposed test rig. A differential gear system (as shown in Fig. 8) is proposed due to its commonality in vehicle transmission assembly and can be easily modified to suit the test requirement that can be described in Fig. 9.

Normally, a vehicle differential gear has a one input shaft (connected to pinion gear) and two output shafts (connected to spider gear) as shown in Fig. 8. It is designed to drive a pair of outputs from a single input power source through the pinion gear and ring gear while allowing them to rotate at different speeds. In this study, the differential gear will be modified to 
receive two inputs and combine it to single output as shown in Fig. 9. The power generated by the engine will be channel to one of the shaft connected to spider gear. The hydraulic motor will be connected to the pinion gear and then drive the ring gear. The sum of these two input shafts will drive the output shaft that connected to the engine dynamometer. For the finalized concept design, can be described in detail in Fig. 10. To generate hydraulic pressure inside the accumulator, a hydraulic power pack is used to simulate energy created by braking force of the vehicle. A low and high pressure accumulator will be used to store the hydraulic energy.

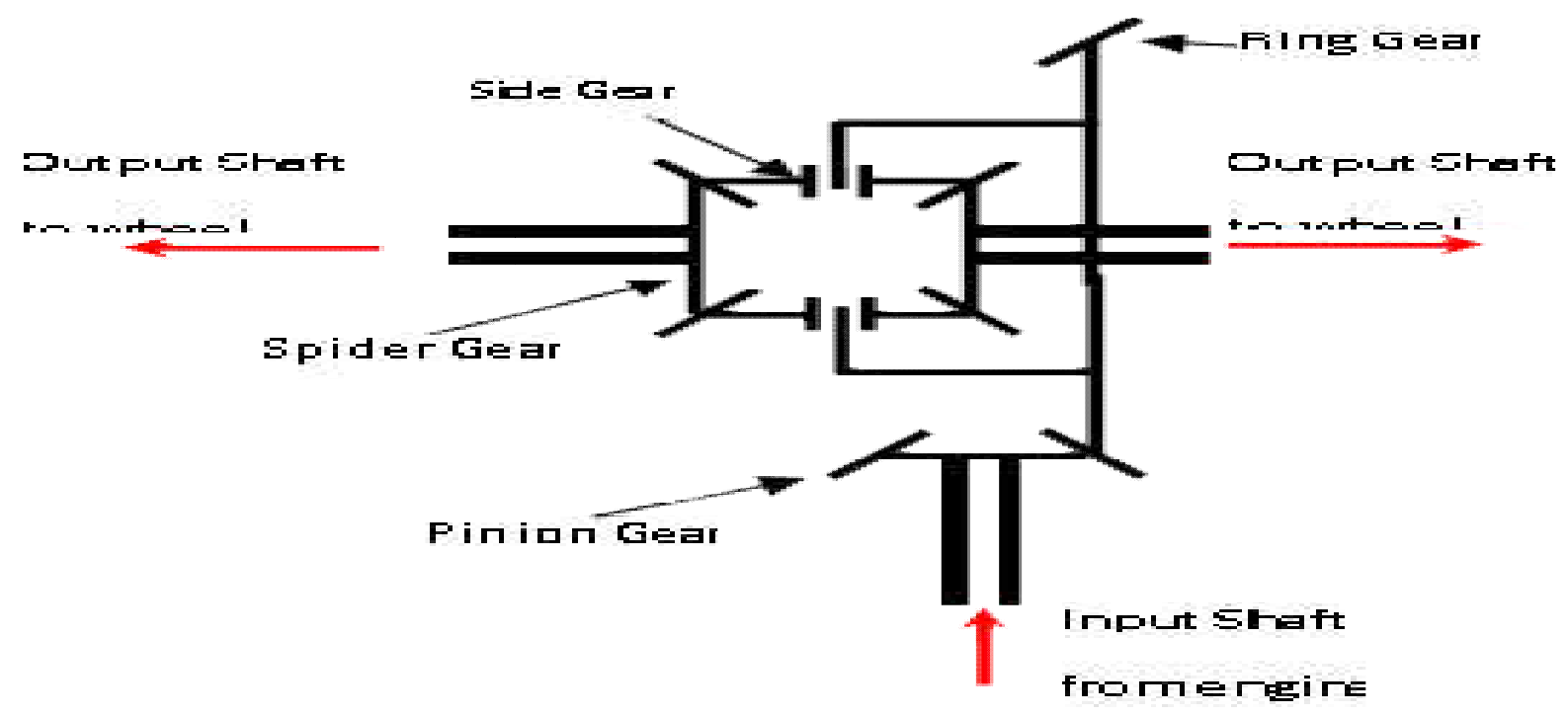

Fig.8. Conventional vehicle differential gear schematic

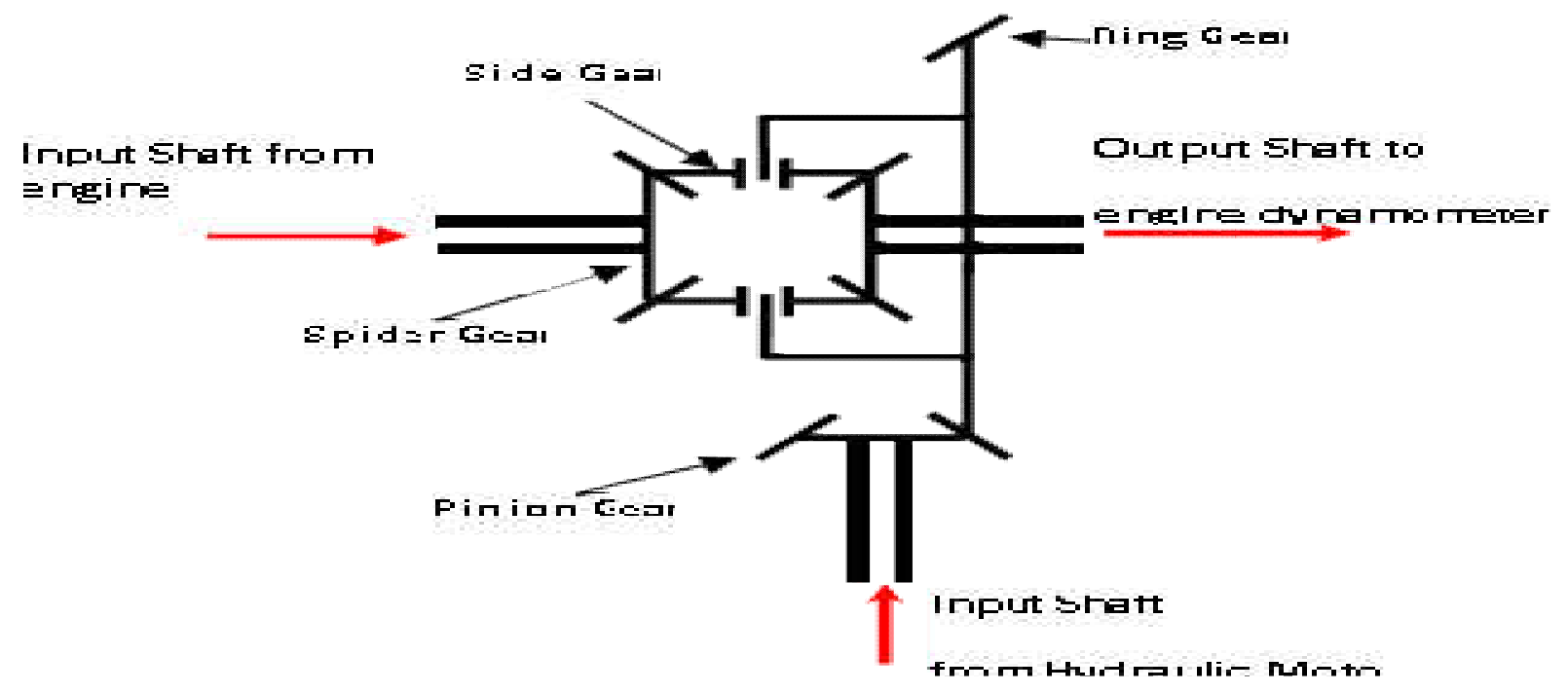

Fig.9. Modification of differential gear setup into proposed test rig configuration 


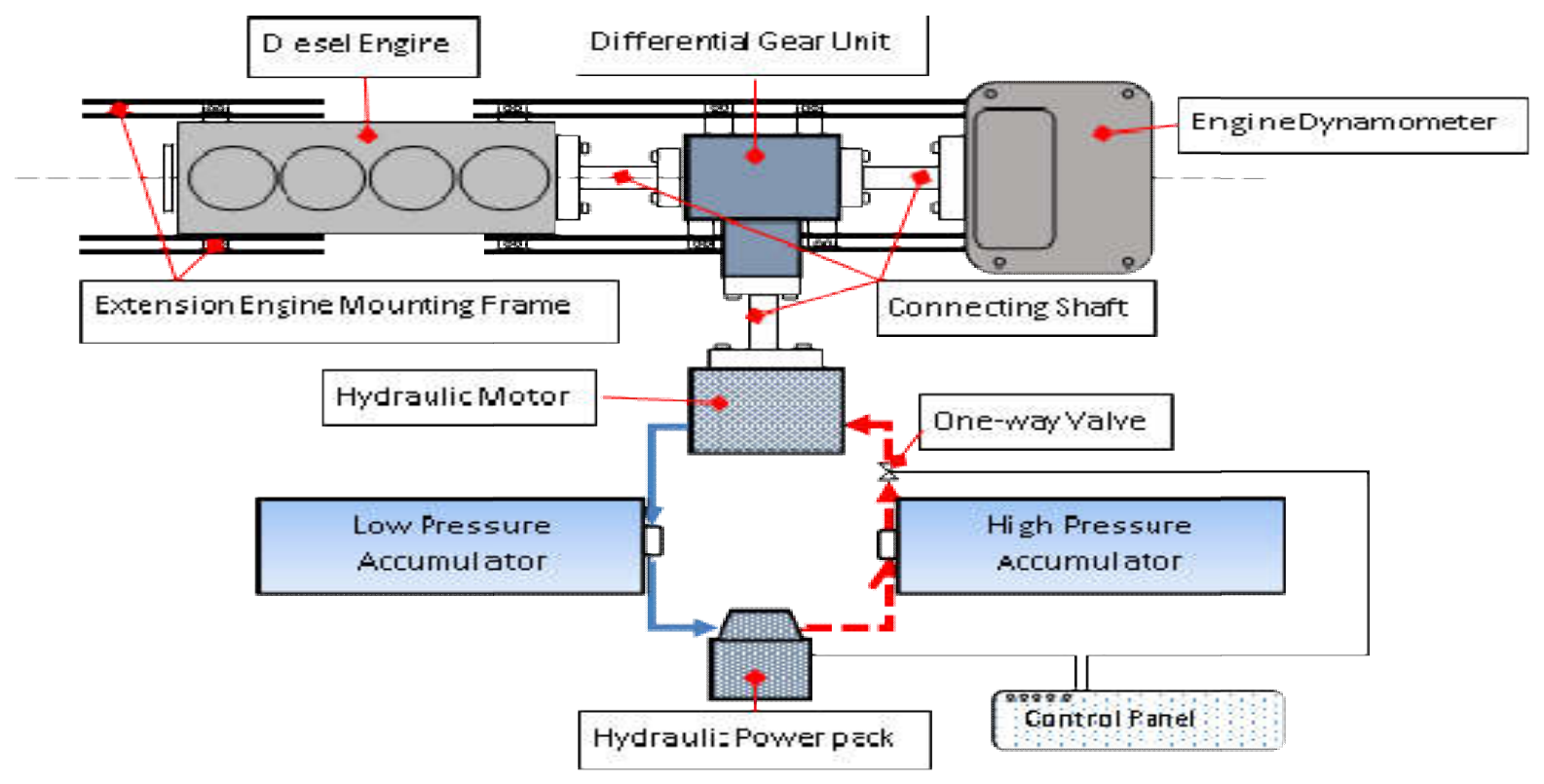

Fig.10. Proposed Setup of the hydraulic hybrid on the dynamometer

Table 1. Proposed test rig materials and specification

\begin{tabular}{|c|c|c|}
\hline Item & Type & Remarks/Description \\
\hline Diesel Engine & 4-cylinder Turbocharged Direct & - Power: $121 \mathrm{~kW}$ at $4000 \mathrm{rpm}$ \\
\hline \multirow[t]{2}{*}{$3200 \mathrm{cc}$} & Injection & - Torque: $351 \mathrm{Nm}$ at \\
\hline & & $2000-3000 \mathrm{rpm}$ \\
\hline
\end{tabular}

Accumulator $\quad$ Bladder type accumulator [11]

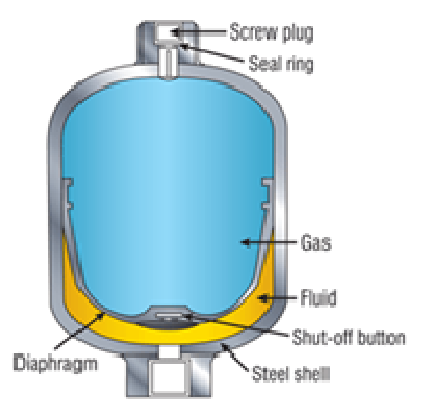

Differential Open type differential unit [12]

Gear Unit
- Nominal Volume: 20L

- Eff. Gas Volume: 20L

- Weight: $114 \mathrm{~kg}$

- Mitsubishi Pajero front axle. 


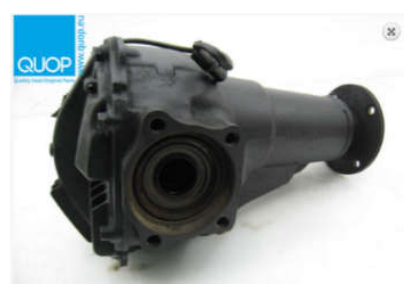

Hydraulic

Motor

Engine

Dynamometer

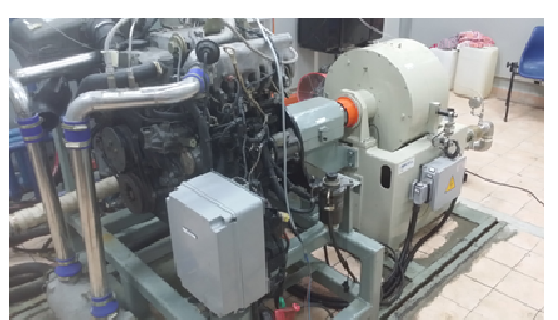

- Gear ratio: 8.31

- Displacement: $20 \mathrm{cc} / \mathrm{rev}$ to $100 \mathrm{cc} / \mathrm{rev}$

- Max. Continuous Working Pressure: 210 bar

- Max. Speed: 5 to $2400 \mathrm{rpm}$

- Max. Working Temp: $70{ }^{0} \mathrm{C}$

- Output Power: $10 \mathrm{~kW}$ to $62 \mathrm{~kW}$

- Max power: $380 \mathrm{~kW}$

- Max speed: $12000 \mathrm{rpm}$

- Max Torque: $800 \mathrm{Nm}$

\section{CONCLUSION}

Based from the proposed conceptual design mode, it is expected that the coupled hydraulic hybrid and engine configuration can increase the engine performance (power and torque) up to $20 \%$ from the stand-alone engine configuration. The alignment of vital parts (engine [14], hydraulic motor, differential gear and dynamometer) will influence the outcome of the experimental data since any significant misalignments can lead to massive vibration issue. This on the other hand will reduce the ability of the test rig to perform experimentation at high speed. 


\section{ACKNOWLEDGEMENTS}

The authors wish to acknowledge the research grant provided by Short Term Grant Scheme (UPNM/2015/GPJP/2/TK/08) from the National Defence University of Malaysia, which lead to the realization of this work

\section{REFERENCES}

[1] Wu W, Hu J, Jing C, Jiang Z, Yuan S. Investigation of energy efficient hydraulic hybrid propulsion system for automobiles. Energy, 2014, 73:497-505

[2] Li C T, Peng H. Optimal configuration design for hydraulic split hybrid vehicles. In IEEE American Control Conference, 2010, pp. 5812-5817

[3] Cheong K L, Li P Y, Chase T R. Optimal design of power-split transmissions for hydraulic hybrid passenger vehicles. In IEEE American Control Conference, 2011, pp. 3295-3300

[4] Li X, Qu J, Wei W, Tian X. Modeling and simulation of power coupling system in hydraulic hybrid city bus. Energy and Power Engineering, 2014, 6(6):119-132

[5] Zhang X, Huei P, Jing J. A near-optimal power management strategy for rapid component sizing of multimode power split hybrid vehicles. IEEE Transactions on Control Systems Technology, 2015, 23(2):609-618

[6] Ramdan M I, Stelson K A. Optimal design of a power-split hybrid hydraulic bus. Proceedings of the Institution of Mechanical Engineers, Part D: Journal of Automobile Engineering, 2016, 230(12):1699-1718

[7] Hilman N, Saw L H, Hamdi M, Norhirni M Z. Performance evaluation of parallel hydraulic hybrid vehicle using EPA US06 aggressive drive cycle simulation. In 5th AOTULE International Postgraduate Students Conference on Engineering, 2010, pp. 131-134

[8] Esfahanian V, Nehzati H, Ha'iri-Yazdi M R, Safaie A, Esfahanian M, Tehrani M M. Design and modeling of a parallel hydraulic hybrid bus. In International Conference on Applications and Design in Mechanical Engineering, 2012

[9] Schumack M, Schroeder C, Elahinia M, Olson W. A hydraulic hybrid vehicle simulation program to enhance understanding of engineering fundamentals. In ASEE Annual Conference Proceedings, 2008 
[10] Lozano D A. Simulation of a diesel-hydraulic series hybrid. Master thesis, San Luis Obispo: California Polytechnic State University, 2010 Brendan C. Machinery lubrication. 2009 , http://media.noria.com/sites/archive_images/articles_200907_pg26b.gif

[12] Quality Used Original Parts (QUOP). Front differential. 2016, https://www.quop.eu/wp-content/uploads/all_images/Front-differential-MR453792-22225684 -1-720x720.jpg

[13] Melco Industrial Supplies Co., Ltd. High speed radial piston hydraulic motors. 2008, Retrieved from http://www.melco.com.hk/data/05145243G-motor.jpg.

[14] Mohd N K, Moumen I, Muhammad I A, Zairi I R, Computational analysis of air intake system for internal combustion engine in presence of acoustic resonator. ARPN Journal of Engineering and Applied Sciences, 2015, 10(20):9468-9475

\section{How to cite this article:}

Asrul SY, Risby MS, Sarip AR, Saiddi MI, Mat WAW. Conceptual design of hydraulic hybrid test rig for engine performance enhancement. J. Fundam. Appl. Sci., 2017, 9(3S), 70-81. 